\title{
BMJ Open Assisting a child with tuberous sclerosis complex (TSC): a qualitative deep analysis of parents' experience and caring needs
}

\author{
Guendalina Graffigna, ${ }^{1,2}$ Caterina Bosio, ${ }^{2}$ Isabella Cecchini ${ }^{2}$
}

To cite: Graffigna G, Bosio C, Cecchini I. Assisting a child with tuberous sclerosis complex (TSC): a qualitative deep analysis of parents' experience and caring needs. BMJ Open 2013;3:e003707.

doi:10.1136/bmjopen-2013003707

- Prepublication history for this paper is available online. To view these files please visit the journal online (http://dx.doi.org/10.1136/ bmjopen-2013-003707).

Received 1 August 2013 Revised 8 October 2013 Accepted 9 October 2013

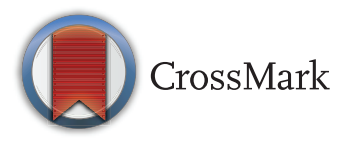

${ }^{1}$ Department of Psychology, Universita' Cattolica Del Sacro Cuore, Milan, Italy

${ }^{2}$ Healthcare Department, Gfk Eurisko, Milan, Italy

Correspondence to Dr Guendalina Graffigna; guendalina.graffigna@unicatt. it

\section{ABSTRACT}

Objective: This study was aimed to explore parents' experience of assisting children affected by tuberous sclerosis complex (TSC) with subependymal giant-cell astrocytoma (SEGA) manifestation, in order to understand their caring needs and expectation of support.

Setting and procedure: The study was designed according to the qualitative method of interpretative description and implied two sequential phases of data collection. The first phase was based on in-depth interviews with 18 Italian caregivers of children living with TSC. The second phase of the research was based on an online forum with 30 caregivers of children living with TSC.

Participants: 48 Italian caregivers, assisting patients with TSC with SEGA manifestation have been involved in the study.

Results: When a TSC diagnosis is made, the whole family is affected psychologically. TSC has a great impact on families' quality of life and on their ability to cope with the disease and support the child's ability to recover and reach an acceptable level of well-being. Caregivers report the experience of losing control and the feeling of loneliness and abandon from the healthcare system.

Conclusion and practice implications: Families of children affected by TSC need targeted psychosocial assistance in order to support patients and caregivers and facilitate their social integration.

\section{INTRODUCTION}

Tuberous sclerosis complex (TSC) is an autosomal dominant disorder that results from mutations in the TSC1 or TSC2 genes and is associated with hamartoma formation in multiple organ systems such as the brain, eyes, heart, kidneys, skin and others. ${ }^{1}$ This relatively common single gene disorder affects both adults and children, with an estimated birth incidence of approximately 1 in $6000 .^{2}$

${ }^{3}$ Population-based studies have reported the estimated prevalence of TSC to be between

\section{Strengths and limitations of this study}

- This study targeted caregivers of patients with tuberous sclerosis complex (TSC) that constitute a rare disease population. TSC is a fairly neglected area of study, particularly with regard to quality of life and psychosocial adaptation to the disease of patients and of their families.

- This study involved 48 caregivers. This number, although not statistically representative, does constitute a robust sample given the rarity of TSC epidemiology in Italy, particularly when subependymal giant-cell astrocytoma manifestation is concerned.

- The study adopted a qualitative research approach, in order to deeply analyse caregivers' experiences, by 'giving voice' to their experiences and unmet needs.

- The study only included Italian caregivers. A cross-cultural comparison of caregiver's needs and priorities when assisting a child with TSC may make these findings better grounded.

- In order to improve the study evidences, a more articulated data collection and analysis according to patient's age and disease manifestation would be worthy.

1:14000 and 1:25000. ${ }^{4}$ Evidence suggests that patients are diagnosed most frequently at $<15$ months old; the prevalence of TSC decreases as age increases, with prevalence being 1:14000, 1:19000 and 1:24000 for those aged $<6,12$ and 18 years old, respectively. ${ }^{4}$ In Italy, it is estimated that about 5000 people may be affected by TSC. ${ }^{6}$ The diagnosis of TSC may be difficult because of the great variety of illness manifestations. ${ }^{7}$ In July 1998, the TSC Alliance and the National Institutes of Health reached an agreement in the evaluation and the revision of the clinical diagnostic criteria for the TSC previously established. ${ }^{8}$ The aim was to provide the most specific clinical criteria for diagnosing TSC, as reported in Table 1. 
Table 1 Diagnostic criteria for tuberous sclerosis complex

\begin{tabular}{ll}
\hline Major features & Minor features \\
\hline 1. Facial angiofibromas or forehead plaque & 1. Multiple, randomly distributed pits in dental enamel \\
2. Non-traumatic ungula or periungual fibroma & 2. Hamartomatous rectal polyps \\
3. Hypomelanotic macules (three or more) & 3. Bone cysts \\
4. Shagreen patch (connective tissue nevus) & 4. Cerebral white matter radial migration lines \\
5. Multiple retinal nodular hamartomas & 5. Gingival fibromas \\
6. Cortical tuber & 6. Non-renal hamartoma \\
7. Subependymal nodule & 7. Retinal achromic patch \\
8. Subependymal giant cell astrocytoma & 8. 'Confetti' skin lesions \\
9. Cardiac rhabdomyoma, single or multiple & 9. Multiple renal cystsc \\
10. Lymphangioleiomyomatosis & \\
11. Renal angiomyolipoma & \\
\hline
\end{tabular}

However, in the majority of cases, the diagnosis of TSC is often difficult and delayed, and many times is made after the start of seizures. ${ }^{9}$

Indeed, patients with TSC are frequently diagnosed with comorbid neurological disorders, including epilepsy, intellectual disability, behavioural dysregulation, sleep disorders and autism spectrum disorders.

In 2000, the European Medicine Agency (EMA) adopted Orphan Medicinal Products for diseases affecting less than 5 persons of 10000 in the Member States. As a result, the European Union officially confirmed the existence of a public health category (ie, rare diseases). ${ }^{10}$ TSC as well as other rare diseases needs further consideration from healthcare professionals, not only to improve the development of dedicated treatments, but also in order to explore patients' needs and priorities for best orienting care intervention. ${ }^{11}$ However, although rare diseases have been a focus of international policies, specific studies are still scarce. In the specific case of TSC, researches have mainly concentrated on its epidemiology, ${ }^{12}$ diagnostic criteria ${ }^{13}$ and the efficacy of new treatments, ${ }^{12}{ }^{14}$ but only a few have focused on the psychosocial correlates of the illness. ${ }^{15}$ Furthermore, the study of families' perspective in caring for a patient with TSC has been neglected so far, even though as aforementioned, TSC is mainly diagnosed in childhood and many studies have shown that a child's adaptation to illness and disabilities depends on the family's ability to manage and cope with stress caused by the disease. ${ }^{11}$ According to Wallander et al: ${ }^{16}$ 'children's adjustment and function in daily life are related to family empowerment and other resources, such as psychological well-being and material resources'. A family's adaptation to a child's illness is a complex and multidimensional issue in which many internal/external factors (still unexplored) come into play. ${ }^{16} 17$ In order to best plan healthcare interventions attuned to family priorities in the management of TSC, further studies are needed in order to deepen families' experiences, their process of meaning making and their expectation towards the healthcare system. ${ }^{11}$

On the basis of these premises, the qualitative study described in this paper was aimed to explore the views and experiences of Italian parents/caregivers of children with TSC in order to identify and to improve our understanding of their needs and expectations toward a good-quality service and healthcare support. Such knowledge may be important for the development of patient care and the design of professional education programmes and to inform service commissioners.

\section{METHODS}

\section{Study design}

This study was designed according to the qualitative method of interpretive description, ${ }^{18}$ a naturalistic kind of applied research that comes from grounded theory. This method is often used in health and social sciences to develop theories from the implicit assumptions on the basis of which people lead their lives. According to our study objectives, this method of research appeared best suited, in order to deepen caregivers' experience of caring for a child with TSC: a rare disease condition about which further knowledge is needed in order to best orient healthcare and support practice. Interpretative description is an unstructured research approach that helps in ecologically grasping the meaning, the feelings and the experiences lived by the research target, without the need to move from 'a priory hypothesis' of research. Interpretative description is a bottom-up approach of research particularly useful when exploring a new or neglected phenomena, about which scarce knowledge has been developed. It allowed a maximum ecological and deep understanding of the patients' point of view, allowing them to freely speak their experiences, their care, unmet needs and their expectations towards the healthcare system.

\section{Ethical concerns}

Before being included in the study, patients were informed about the research aims and procedure by their reference neurologist together with a researcher responsible for the study. Caregivers enrolled by signing a detailed consent form, and they were free to leave the study if they felt uncomfortable during the interview. We 
analysed anonymised data to respect participants' data privacy.

\section{Participant and setting}

The study was targeted on Italian parents who were caregivers of patients with TSC. All families selected included a child diagnosed with TSC with Subependymal Giant-Cell Astrocytoma (SEGA) manifestations.

A non-random sampling strategy was used to recruit a purposive maximum-variation sample of caregivers assisting a child with TSC in Italy. This approach provided the broadest representation of families' experiences of living with a child with TSC and ensured that a wide range of perspectives could be represented in the dataset. In this way caregivers' experiences and needs of support could be considered from all angles prior to identifying the common themes evident in the data. ${ }^{19}$

Caregivers were recruited through their reference neurologist. An information email inviting expressions of interest to collaborate was sent to the 15 neurological centres best specialised in the diagnosis and treatment of TSC in Italy. Neurologists were invited to identify potential caregivers to be included in the study. Inclusion criteria were (1) to be a caregiver directly assisting a patient with TSC; (2) all patients had to be diagnosed with TSC at least 5 years before inclusion in the study; (3) the age of the patients assisted varied, such as disease manifestations, but all had to present an SEGA diagnosis. These slow-growing, glioneuronal tumours develop in 5-20\% of patients with TSC and are associated with a clinically significant risk of illness and death, including sudden death from acute hydrocephalus. ${ }^{20}$ SEGA does not spontaneously regress and the volume increases progressively once serial growth is shown. Current standard treatment is surgical resection; however, the deep location of these tumours can make resection difficult with an important risk of perioperative or postoperative complications. ${ }^{21}$ The choice of focusing on this specific manifestation of TSC was due to the high invalidating impact of SEGA on patients' and families' quality of life. These patients and their family, thus, appear the most needful of assistance from the healthcare system.

Of the 15 neurological centres invited, only 12 agreed to participate in the study (Istituto Giannina Gaslini, Genova; A.O. Policlinico, Bari; ASL 8, Cagliari; A.O.R.N. Santobono Pausilipon, Napoli; A.O. San Paolo, Milano; Policlinico TorVergata, Roma; Ospedale Pediatrico Bambino Gesù di Roma; Ospedale Maggiore, Bologna; Azienda Ospedaliera Di Padova; Azienda Ospedaliera Fatebenefratelli e Oftalmico di Milano; Università degli Studi di Catania; Fondazione Istituto Neurologico C. Mondino, Pavia), each of them providing contact with three to four caregivers to be included in the study.

On the whole, 48 Italian caregivers of patients with TSC were interviewed.

Data were collected between November 2011 and January 2012 (table 2).

\section{Data collection}

Our study implied two sequential phases of data collection. The first phase was based on in-depth semistructured interviews with 18 caregivers. The interviews lasted about $1 \mathrm{~h}$ each and were conducted by senior qualitative researchers on the basis of a loosely structured interview guide (GG and $\mathrm{CB}$ ). Demographics data and free accounts of the diagnostic process, disease experience and healthcare history were included in all the interviews to ensure a good basis for interpreting accounts. In-depth focused interviewing techniques were used to enhance clarification, elaboration and illustration of experiences, and to ensure that each participant, as much as possible, articulated his or her lived experiences and his or her unmet needs towards the healthcare system. A continuous sharing and up-dating between the two interviewers was guaranteed, in order to 'cross-fertilise' the whole data collection process. After each interview interviewers met at debriefing sessions to share their data and interpretation.

As patterns and themes began to emerge from the interview data, we conducted a second phase of research based on an online forum with 30 caregivers of children living with TSC. The online forum gave the opportunity to a selection of caregivers to share experiences that were key to the purposes of the study, providing a "protected space' in which participants could interact and discuss their experiences, feelings and emotions relative to the disease in an anonymous and fairly spontaneous manner. ${ }^{22}{ }^{23}$ Online forums allow asynchronous participation in the discussion, meaning that participants do

Table 2 Participant characteristics

\begin{tabular}{|c|c|c|c|}
\hline Characteristics & $\begin{array}{l}\text { Number } \\
(\mathrm{N}=43)\end{array}$ & $\begin{array}{l}\text { Per } \\
\text { cent }\end{array}$ & $\begin{array}{l}\text { Age } \\
\text { (mean/SD/range) }\end{array}$ \\
\hline Age of caregivers & & & $\begin{array}{l}47(6.3) \\
(38-65)\end{array}$ \\
\hline \multicolumn{4}{|l|}{ Sex of caregivers } \\
\hline Female & 30 & 62.5 & \\
\hline Male & 18 & 37.5 & \\
\hline Age of patients & & & $\begin{array}{l}12(8.5) \\
(1.5-22)\end{array}$ \\
\hline \multicolumn{4}{|l|}{ Sex of patients } \\
\hline Female & 31 & 64.6 & \\
\hline Male & 17 & 35.4 & \\
\hline \multicolumn{4}{|c|}{ Patients major disabilities } \\
\hline Epilepsy & 39 & 81.2 & \\
\hline $\begin{array}{l}\text { Cognitive } \\
\text { retardation }\end{array}$ & 46 & 95.8 & \\
\hline SEGA & 48 & 100 & \\
\hline Facial marks & 48 & 100 & \\
\hline Bedridden & 0 & 0 & \\
\hline \multicolumn{4}{|c|}{ Geographic origin of patients/caregivers } \\
\hline Northern Italy & 19 & 39.6 & \\
\hline Central Italy & 13 & 27.1 & \\
\hline Southern Italy & 16 & 33.3 & \\
\hline
\end{tabular}


not have to be online at the same time, but can post their comments whenever it is most convenient for them to do so. The online forums were conducted on a private website and participation was anonymous. The discussion lasted five working days (for a more detailed description of the online forum technique ${ }^{24}$ ).

\section{Data analysis}

We used a constant comparative analytic process to identify themes and their patterns in the narrative accounts collected. The analysis proceeded to test ongoing hypotheses as they evolved from the analytical process. ${ }^{25}$ The constant comparative analysis was conducted in parallel with data collection in order to reorient it on the basis of the interpretative insights emerged from the analysis. The analysis process was conducted in parallel by two of the authors (GG and $\mathrm{CB}$ ) and discussed with the rest of the team during supervision meetings until an adequate agreement $(\kappa>0.80)$ was achieved. This shift between periods of immersion in the data and periods of strategic distancing ${ }^{18}$ enabled us to have a more reflective view throughout the analytical process and ensured that data saturation had been achieved, as no new themes emerged from the remaining interviews. This iterative analysis process-that developed thanks to the deep study of the integral interview transcriptsrequires three sequential phases of coding: a first analysis step named 'open coding' that implies a preliminary identification of concepts that fit with data; a second analysis step, named 'axial coding', that consists the progressive aggregation and condensation of codes into broader categories; a final analysis step-'selective coding'-consisting the abstraction from data and the interpretive detection of connections among categories.

\section{RESULTS}

On the whole, 48 caregivers participated in the study: 30 mothers of patients living with TSC and 18 fathers. Caregivers had an average age of 48 years and the children they assisted had an average age of 15 years. Assisted patients were of both genders (29 female and 19 male).

From the analysis, three main themes emerged related to caregivers' experience of assisting a patient with TSC and their needs and expectations toward the healthcare system, each articulated in subthemes, as reported in table 2. Each theme is considered in detail below. We report in italics words and direct quotation reported by caregivers during the interviews (table 3 ).

\section{Experience of losing control}

Caregivers describe TSC as an out of control disease because of the following reasons.

\section{TSC: an indecipherable disease}

In caregivers' words, TSC is difficult to diagnose and to be understood in its nature and evolution; particularly because it is felt as mutable in its manifestations and its development (TSC is a mutable, multifaceted disease' mother, male patient with TSC, 12 years old); subdual, because often hidden, with apparently invisible symptoms ("TSC is subdual because it is there, but you do not perceive it. It seems to remit, and suddenly it comes back even more severe" mother, male patient with TSC, 16 years old); and ingravescent since all caregivers are aware (and know from experience) that the disease tends to worsen over time. As a consequence, caregivers symbolically describe themselves as being trapped in a labyrinth ("Paediatricians tell you that you never recover from this disease" father, female patient with TSC, 10 years old) and fear that the disease will become less and less sustainable over time ("You are in a downward spiral with no way out" mother, female patient with TSC, 14 years old).

\section{TSC: an unsustainable disease}

All interviewees report the feeling of increasing unsustainability of the disease, that is not expressed in terms of lower life expectation (caregivers do not seem to perceive TSC as a lethal pathology) but of more and more future unknown ("Not knowing what to expect is what haunts me" mother, male patient with TSC, 6 years old) as regards the child's development process and the need to rethink the goals, plans and hopes parents naturally have for their children's future; the disease progression, since TSC is perceived as mutable and unpreventable, parents have a hard time coming to terms with the disease and envisioning a way out; the efficacy of therapeutic intervention: the absence on the market of a target therapy for TSC (when the study was conducted) and the symptomatic use of other therapies in order to control its manifestations cause concern among caregivers in terms of the future response of their children to the intervention and of any side effects due to the chronicity of therapies ("We know that it will be impossible to go out of this problem. We only hope to increase the assistance we can receive for our daughter" mother, female patient with TSC, 18 years old).

\section{Difficulty of planning for the future}

It follows that psychologically, caregivers tend to play by ear (such as they describe their attitude) in the daily caring of their children seeing that coming to terms with the disease and its manifestations is emotionally and cognitively difficult. Parents tend to deny the gravity and risks of the disease in an effort to cope with the daily challenges they have to face ("We live day-to-day without knowing what the future has in store for you." mother, female patient with TSC, 17 years old; "It is the disease of anguish: you always live in a state of anxiety about the future." mother, male patient with TSC, 9 years old).

Caregivers' narratives of their children's disease are marked by a recurrence of unexpected clinical events that alter the pathway of the disease. Caregivers talk 
Table 3 Main themes reached in the analysis

\begin{tabular}{lll}
\hline $\begin{array}{l}\text { Theme (selective coding analysis } \\
\text { phase) }\end{array}$ & $\begin{array}{l}\text { Subtheme (axial coding } \\
\text { analysis phase) }\end{array}$ & Examples of quotes (open coding analysis phase)
\end{tabular}

The experience of losing control

TSC: an indecipherable disease

"TSC is a mutable, multifaceted disease" mother, male patient with TSC, 12 years old

"TSC is a hidden disease" father, female patient with TSC, 10 years old

"TSC is subdual because it is there, but you do not perceive it. It seems to remit, and suddenly it comes back even more severe" mother, male patient with TSC, 16 years old "It will worsen time after time" mother, female patient withTSC, 7 years old

"When you think that you learned to manage and to know it, suddenly a new manifestation come" father, male patient with TSC, 18 years old

"Paediatricians tell you that you never recover from this disease" father, female patient with TSC, 10 years old

TSC: an unsustainable disease

"You are in a downward spiral with no way out'"' mother, female patient with TSC, 14 years old

"Not knowing what to expect is what haunts me" mother, male patient with TSC, 6 years old

"We had to revise all our family goals, plans and hopes for our child future" mother, female

patient with TSC, 17 years old

"It is very hard, also because there is not a dedicated treatment to it" father, female patient with TSC, 13 years old

"The treatments that my daughter follows cause a lot of side effects" mother, female patient with TSC, 14 years old

"We know that it will be impossible to go out of this problem. We only hope to increase the assistance we can receive for our daughter" mother, female patient with TSC, 18 years old

"It is a really unsustainable disease" mother, male patient with TSC, 15 years old

"It is hard to live with a child with TSC, believe me" father, male patient with TSC, 8 years old

The difficulty of planning for the "It is like playing by ear" father, female patient with TSC, 16 years old

"We live day-to-day without knowing what the future has in store for you" mother, female patient with TSC, 17 years old

"It is the disease of anguish: you always live in a state of anxiety about the future." mother, male patient with TSC, 9 years old

"We spent the first 3-4 years in and out of the hospital always ready to face an emergency."

father, female patient with TSC, 19 years old

Coping with the disease: a complex The 'alarm' in the prediagnosis "I was worried, but the paediatrician dismissed my concerns, so I filmed my son's crisis and in front of the evidence he changed his opinion" mother, male patient with TSC, 11 years old "My son started to be strange, in my heart I understood that something was going wrong" "I went to the doctor because my child seemed absent, I was alarmed" mother, male patient with TSC, 7 years old

"It was summer and she started to have skin patches. We were at the beach, we went to a dermatologist there and he said that it was because of the sun. But that answer didn't satisfied me, I knew that something was wrong and I went to another doctor" mother, female patient with TSC, 10 years old 
Table 3 Continued

\section{Theme (selective coding analysis Subtheme (axial coding phase)} isolation

\section{Examples of quotes (open coding analysis phase)}

"When my son had just been diagnosed, I couldn't even believe it, it didn't seem possible Ididn't want it to be true!" mother, male patient with TSC, 9 years old

"At the beginning you deny the truth, you still hope that something can change and you prefer not to tell about the diagnosis to relatives and friends" father, female patient with TSC 16 years old

"At the beginning you desperately hope for a way out" mother, female patient with TSC, 14 years old

"You think: 'it cannot be true', and you act as if she was not diagnosed" mother, female patient with TSC, 10 years old

The family 'withdrawal' and

"The others are like "bad wolves", and I do not want to expose my son to them. They are "the ones who are different", not the person who has TSC." mother, female patient with TSC 8 years old;

"Is a period in which you try to construct a glass bell around your daughter, around you and your family. Is a way to protect her. Is a way to get defend from who is not understanding" mother, female patient with TSC, 12 years old

"I want my son to be treated as a normal child; I do not want people to only see the disease: there is a person behind the disease!" mother, male patient with TSC, 15 years old.

"You do your best to ensure that your child does not feel

"different" from his peers" father, male patient with TSC, 14 years old

"I treat my child as a normal person, she is normal, she only have a TSC diagnosis. I want society treat her as a normal human being"' mother, female patient with TSC, 17 years old

The acceptance of the diagnosis "We networked with other families who share the same burden and we fight for the rights of our children" mother, female patient with TSC, 19 years old

"At some points I understood that the only way to help my daughter is to do something to improve TSC patients life and context, so I joined the patients' association and now I'm an active member in my region" father, female patient with TSC, 17 years old

"With the time passing, we learned how to cope with the disease. We adapted our routines and our habits in order to live a better life. It worked" father, male patient with TSC, 18 years old

"At the beginning it was hard, but know, we achieved a better quality of life, at least because we adapted to the disease, we accepted it" mother, male patient with TSC, 13 years old "When you become able to directly confront with the disease, when you overcome the temptation to deny it, then you live better" mother, female patient with TSC, 17 years old

Continued 
Table 3 Continued

Theme (selective coding analysis Subtheme (axial coding

\section{phase)}

analysis phase)

Examples of quotes (open coding analysis phase)

Caregivers' unmet needs and their expectations for the future

The request of supports for social integration

"We need further spaces dedicated to the socialisation and integration of the patient" father, female patient with TSC, 14 years old

"We don't have dedicated space where to meet, we don't have dedicate buses to help in moving patients" mother, female patient with TSC, 10 years old

"I cannot think about when l'll be old, or even died, because none will be able to take care about my child anymore. He need support for making his rights heard'"' mother, male patient with TSC, 16 years old

"I would like legal assistance form my child in the future" mother, male patient with TSC,

15 years old.

"I'm worried about the economic situation of my daughter in the future, when l'll won't be able to care for her" mother, female patient with TSC, 17 years old

The request of psychosocial counselling for caregivers mother, female patient with TSC, 14 years old

"We need an expert support, directly for us. Sometimes we need to make 4 or 5 phone calls before we find someone who can give us some advice" mother, male patient with TSC,

9 years old

"This online forum was a really nice occasion to share doubts, sorrows and experiences with other parents that understand you. Thank you for conducting it! I think we really would need something similar in our daily life to meet and share" mother, female patient with TSC

17 years old

"We feel lonely, we need counselling, we need support" mother, male patient with TSC, 13 years old

"Sometime I break down crying, It is hard! We need psychological help to carry on!" mother, male patient with TSC, 15 years old.

The request for society sensitisation "More information and education would make people less scared about TSC" father, female patient with TSC, 14 years old;

"We need to educate people to treat our children as people, and not as "patients" or "outcasts. mother, female patient with TSC, 8 years old

"I expect campaigns to sensitise public opinion" father, female patient with TSC, 10 years old "TSC is a neglected disease: nobody care about it, nobody talk about it...but it exists and people need to be more aware about it" mother, male patient with TSC, 13 years old

"Further education and sensitisation is needed, in particular at school. Not only for children, but also for teachers that are unprepared to cope with our children, and they do stigmatise them" mother, female patient with TSC, 8 years old 
Figure 1 Process of family adaptation to tuberous sclerosis complex.

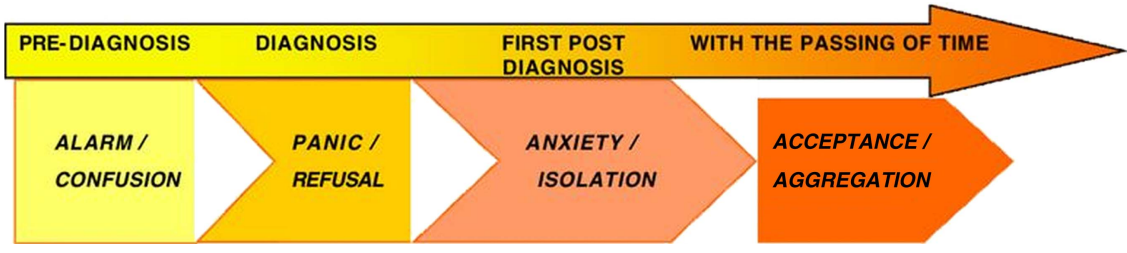

about continuous emergencies, the appearance of new symptoms to be diagnosed and treated, repeated surgeries often causing complications and severe side effects due to therapies.

"We spent the first 3-4 years in and out of the hospital always ready to face an emergency." father, female patient with TSC, 19 years old.

\section{Coping with the disease: a complex process of maturation}

The disease and its manifestations have a great impact on the family's quality of life. Caregivers report that TSC has changed their daily family routines, which are now centred around the needs of the patient (eg, parents work shifts according to the patient's treatment schedule; the family moves nearer to the neurological centre; holidays are planned based on the availability of treatment and assistance). TSC often changes family relationships, strongly challenging the bond between partners and causing separations and divorces. Furthermore, even more important at the psychological level, the diagnosis event forces the family to reorganise its plans for the future, making them focus more on the present.

In the experience of interviewed families, the process of adaptation to the disease is slow and progressive, such as in a maturation process, and it is described by caregivers in four sequential experiential phases (see figure 1). As discussed in the final paragraph, this process appears similar to the patient's psychological adjustment to cancer. ${ }^{26}{ }^{27}$ However, our results cast light on the whole family's adaptation process to a chronic disease diagnosis.

\section{'Alarm' in the prediagnosis phase}

The process of experiential maturation often starts before the TSC diagnosis (prediagnosis period) when strange symptoms begin to appear. During this time the child usually appears absent, suffers epileptic crises, and has skin patches. Often these symptoms persist, causing the caregiver concern about the child's health and requiring a specialist evaluation. Most of the caregivers interviewed report that general practitioners and general paediatricians tend to initially misinterpret these signs and often underestimate their importance. According to caregivers, this marks the beginning of an odyssey from one specialist to another in search for answers ("I was worried, but the paediatrician dismissed my concerns, so I filmed my son's crisis and in front of the evidence he changed his opinion" mother, male patient with TSC, 11 years old). Emotionally, caregivers' experience show a state of alarm, disorientation and confusion, feeling of being misunderstood and a lack of support from the healthcare system.

\section{Refusal of the diagnosis}

In the collected stories, a second emotional phase follows when, after a series of misdiagnoses or underestimations of the disease, the TSC diagnosis is effectively made. The TSC diagnosis is received with great ambivalence by the caregivers. At the cognitive level, it constitutes a final answer and puts an end to any previous confusion and disorientation. On the other hand, however, the caregivers go into denial and deeply hope that there is still a way out and a chance to return to 'normality' ("When my son had just been diagnosed, I couldn't even believe it, it didn't seem possible, I didn't want it to be true!" mother, male patient with TSC, 9 years old; "At the beginning you deny the truth, you still hope that something can change and you prefer not to tell about the diagnosis to relatives and friends" father, female patient with TSC, 16 years old).

\section{Family 'withdrawal' and isolation}

After some time from the initial TSC diagnosis, the family tends to isolate itself and to avoid contact with its support network, including friends and relatives. This isolation appears as a psychosocial strategy to keep previous routines and family goals for the future as unchanged as possible. At the psychosocial level, it is an attempt to construct a glass bell in order to protect the child from others and to pretend that nothing has changed since before the diagnosis ("The others are like 'bad wolves', and I do not want to expose my son to them. They are 'the ones who are different', not the person who has TSC" mother, female patient with TSC, 8 years old; "Is a period in which you try to construct a glass bell around your daughter, around you and your family. Is a way to protect her. Is a way to get defend from who is not understanding" mother, female patient with TSC, 12 years old).

In this phase, families invest a lot of (psychological and social) energy to ensure that the child does not feel different from his/her peers and that society views their child as a person and not a patient. In this period, caregivers feel lonely and alienated from families who do not share the same experience. During this period of 'withdrawal, caregivers also avoid contact with other families of children with TSC as a way to block out any reminders of the disease ("I want my son to be treated 
as a normal child; I do not want people to only see the disease: there is a person behind the disease!" mother, male patient with TSC, 15 years old).

\section{Acceptance of the diagnosis}

Only after several years, the families seem to accept their child's condition and open up to some forms of socialisation and interact with families similar to them. These families have learned how to face the disease and have deeply changed their family routines to suit the patient, who is considered extremely delicate. As a consequence, these families also become more engaged in the management of their child's health and become active in their communities (eg, in some cases they become promoters or active members of patient associations) and they advocate the improvement of pragmatic and social conditions of patients with TSC ("we networked with other families who share the same burden and we fight for the rights of our children" mother, female patient with TSC, 19 years old; "At some points I understood that the only way to help my daughter is to do something to improve TSC patients life and context, so I joined the patients' association and now I'm an active member in my region" father, female patient with TSC, 17 years old).

\section{Caregivers' unmet needs and their expectations for the future}

Across the board, families have few pragmatic and emotional resources to cope with TSC ( $50 \%$ of the sample). Most caregivers-especially during the initial period after diagnosis-mainly rely on internal resources (ie, themselves, their partners, a few close friends). Their proximal network is distant, unsupportive and unsympathetic ("I looked for all the information by myself" mother, male patient with TSC, 5 years old). In other cases-and in particular in a more 'mature phase', when families learn to accept their child's disability the patient's association becomes a primary form of support and it is considered as an important source of information, sharing and participation with other families that have experienced the disease ('We receive strong support from the patient association: it is our second family!' mother, male patient with TSC, 13 years old).

\section{Request for supports for social integration}

In view of the scarce support at present given to TSC families, across the board, interviewed caregivers $(25 \%$ of the sample) are calling for more psychosocial support is also needed in order to help the patient to socially integrate and manage the disease and treatment on a daily basis. ("We need further spaces dedicated to the socialisation and integration of the patient" father, female patient with TSC, 14 years old). They are also asking for help in reducing the burden of their responsibility and making them feel less lonely. Furthermore, a major concern for parents is with regard to the future of their children, when they will no longer be able to care for them. Patients with TSC are often entirely reliant on their caregivers on account of their cognitive and behavioural impairment. Caregivers therefore require not only basic support for the daily needs of their children, but also economic support and legal assistance for the future ("I cannot think about when I'll be old, or even died, because none will be able to take care about my child anymore. He need support for making his rights heard" mother, male patient with TSC, 16 years old).

\section{Request for psychosocial counselling}

Increased psychosocial support is also expected for the caregivers themselves, who are both physically and emotionally drained ( $15 \%$ of the sample). Families require counselling and support so that they can let out their anxiety and would not have to risk taking their stress out on the patient. Targeted psychological assistance, as meetings and discussion groups among families who share the same difficulties, would be beneficial. Currently, these initiatives are extremely scarce ("I wish we had more psychological support and services that provide advice to parents" mother, female patient with TSC, 14 years old; "We need an expert support, directly for us. Sometimes we need to make 4 or 5 phone calls before we find someone who can give us some advice" mother, male patient with TSC, 9 years old). In this regard, the online forum set up for this research was appreciated by caregivers as a tool for sharing stories, concerns and feelings with other families and as a way to make their needs and desires be heard.

\section{Request for society sensitisation}

Finally, in order to make the social context more inclusive and emphatic towards patients with TSC, caregivers ( $10 \%$ of the sample) are calling for public campaigns to raise awareness on the disease and what people with TSC need ("More information and education would make people less scared about TSC" father, female patient with TSC, 14 years old; "We need to educate people to treat our children as people, and not as 'patients' or 'outcasts." mother, female patient with TSC, 8 years old). This is particularly crucial at school, where teachers, students and their families are unprepared to cope with patients with TSC and their special requirements in the classroom.

\section{DISCUSSION}

TSC is a rare disease, but caregivers also describe it as a neglected disease not only because a target and a specific therapy for TSC are still missing in 2012, at the time of this study in Italy, but also because there is a lack of understanding of the feelings, difficulties and requests of patients and their families. To date, psychosocial studies that improve the past experiences of patients and caregivers coping with TSC are lacking. In particular, the voices of caregivers have been neglected, despite the fact that literature underscores the importance of family 
support for children with disabilities: ${ }^{28}$ families that are able to well adapt to the disease increase the chances of patients' recovery and well-being. ${ }^{11}$ Furthermore, since TSC (in particular when SEGA manifestation are concerned) is strongly invalidating patients, often causing developmental retardation and cognitive impairments, to study caregivers' / parents' experiences and caring unmet needs appear the only way to cast light on such a difficult and neglected pathological experience. Health policies and interventions should not only be centred on the patient's needs and priorities, but also on those of their families, especially when children are involved. ${ }^{29} 30$

At present, because of the rarity of the disease and the complexity of the diagnostic process, the healthcare system is struggling to functionally and fully assist patients with TSC and their families. This study sheds light on the private difficulties and concerns of families affected by TSC. Due to the rarity of the disease, a sample of 48 caregivers of patients with TSC are interviewed, although probably not statistically representative, this however represents an important and significant step forward in the deep analysis of these target population experiences and caring needs.

In spite of the different disease trajectories and life stories, indeed, caregivers shared similar needs and adjustment processes. In particular, the study underlined a sense of disorientation and loneliness shared by all families and their need for further assistance in order to give a meaning to and come to terms with the disease. These psychological mechanisms are the basic precondition for families in order to develop pragmatic skills to manage and support patients with TSC on a daily basis. As we know, family adaptation to a child's illness is a complex process influenced by several factors. ${ }^{16} 173132$ This study helped in describing the different adaptation phases of TSC family adaptation to a child's diagnosis, by contributing to building knowledge about this neglected disease, and in particular to caregiver's inner experiences. In particular, a family's ability to cope with TSC is the result of a long and difficult process that begins with a sense of alarm at the appearance of the first disease symptoms to a state of disorientation at the moment of diagnosis, to psychological negation immediately after the diagnosis and finally to the acceptance of the disease over time. Although this psychological process does not appear new in psychology with regard to a patient's adjustment and coping to health diagnosis, ${ }^{26}{ }^{27}$ this study contributed to explore its consistency and element of variation in the case of caregivers, and in particular when a rare disease is concerned. Previous published models of a patient's psychological adaptation to a health diagnosis mainly focused on the individual's distress and emotional reaction to a fatal diagnosis (ie, cancer). The process detected in this study, on the contrary, describes the whole family's interpersonal adaptation to the disability of a child caused by a rare and potentially chronic disease. The model proposed in this paper, thus, appears useful to understand the sociopsychological (and not only intrapsychic) adaptation movements of a family towards its integration in the community, the emotional burdens implied and the family's expectations towards healthcare.

Each of these experiential phases requires a deeper understanding of a family's emotive reaction and their psychological and pragmatic needs for making the disease more sustainable. This would make it possible to orient interventions to support caregivers in their adaptation to their child's diagnosis and to become more able to assist them. Particularly, caregivers are calling for a better fine-tuning of the healthcare system on the specific needs and priorities of both patients and their families. Confirming previous studies in other medical fields, ${ }^{33}{ }^{34}$ the family as a whole appears affected by TSC and in this sense it needs to be taken into account and supported. A TSC diagnosis is disruptive not only on an emotive level as far as family routines, plans and ambitions are concerned but also in terms of family bonds and relations, with important risks for the patient's chances and ability to cope with the disease.

This study, by casting light on TSC families' needs and priorities, offers interesting pragmatic insights for orienting initiatives and services not only acted to improve patients and family quality of life, ${ }^{35}$ but also to increase family engagement towards the healthcare system. ${ }^{36}$ To engage patients and their caregivers in the process of care is nowadays a priority in the management of chronic diseases, for several orders of consideration: first, for enhancing clinical outcomes ${ }^{37} 38$; second, for improving the sustainability of healthcare systems in a period of economic constraints. ${ }^{39}$ To make patients and their family ally to the healthcare system appear crucial in order to avoid waste of resources and to maximise the benefit of health intervention. ${ }^{40}{ }^{41}$ The debate about patient engagement is now flourishing, but insights related to the pragmatic aspects of the care process that can improve it are still missed. ${ }^{36} 4243$ We believe that this study can concretely contribute not only to the theoretical debate, but also to the practice of patient engagement in the scope of rare diseases.

\section{Conclusions}

When a TSC diagnosis is made, the whole family is psychologically affected. TSC has a great impact on a family's quality of life and on their ability to cope with the disease and support the child's ability to recover and reach an acceptable level of well-being.

Family-centred healthcare services are thus required in order to help TSC families support patients coping with the disease and its evolution. In order to accomplish this, further scientific research is needed to develop a therapy able to manage the multiple manifestations of the disease and to block its evolution. In addition, a deeper understanding of the psychosocial effects TSC has on families is needed in order to be able to develop services that meet their needs and expectations. 


\section{Practical implications}

Families of children affected by TSC need targeted psychosocial assistance. Thus, awareness campaigns are needed in order to support patients and facilitate their social integration.

The professionals involved in managing the care of patients need to be better co-ordinated so that this task no longer falls on families, who currently are the only ones with this burden.

Acknowledgements The authors would like to thank the following centers for contributing to the enrolment of patients: Baglietto Maria Giuseppina, Istituto Giannina Gaslini, Genova; Bellomo Rosella, AO Policlinico, Bari; Boccone Loredana, ASL 8, Cagliari; Buono Salvatore, AORN Santobono, Napoli; Canevini Maria Paola, AO San Paolo, Milano; Curatolo Paolo, Policlinico TorVergata, Roma; Cusmai Raffaella, Ospedale Pediatrico Bambino Gesù di Roma; Gobbi Giuseppe, Ospedale Maggiore, Bologna; Laverda Anna Maria, Azienda Ospedaliera Di Padova; Romeo Antonino, Azienda Ospedaliera Fatebenefratelli e Oftalmico di Milano; Ruggeri Martino, Università degli Studi di Catania; Veggiotti Pierangelo, Fondazione Istituto Neurologico C Mondino,Pavia. The authors also thank Lella Gasparro, Chiara Gnocchi, Katia Lorizzo and Laura Roncoroni (Novartis Pharma, Origgio, Italy) for their important contribution in study co-ordination.

Contributors All the three authors of this article participated in the preparation of the article by (1) giving their substantial contributions to conception and design, acquisition of data, or analysis and interpretation of data; (2) by drafting the article and revising it critically for important intellectual content and (3) by finally approving the version to be published.

Funding Novartis Pharma, Origgio, Italy.

Competing interests None.

Ethics approval The study was approved by the ethics committee of the Università Cattolica del Sacro Cuore di Milano.

Provenance and peer review Not commissioned; externally peer reviewed.

Data sharing statement No additional data are available.

Open Access This is an Open Access article distributed in accordance with the Creative Commons Attribution Non Commercial (CC BY-NC 3.0) license, which permits others to distribute, remix, adapt, build upon this work noncommercially, and license their derivative works on different terms, provided the original work is properly cited and the use is non-commercial. See: http:// creativecommons.org/licenses/by-nc/3.0/

\section{REFERENCES}

1. Crino P, Nathanson KL, Petri Henske E. The tuberous sclerosis complex. N Engl J Med 2006;355:1345-56.

2. Krueger DA, Franz DN. Current management of tuberous sclerosis complex. Paediatr Drugs 2008;10:299-313.

3. Osborne JP, Fryer A, Webb D. Epidemiology of tuberous sclerosis. Ann N Y Acad Sci 1991;615:125-7.

4. Devlin LA, Shepherd $\mathrm{CH}$, Crawford $\mathrm{H}$, et al. Tuberous sclerosis complex: clinical features, diagnosis, and prevalence within Northern Ireland. Dev Med Child Neurol 2006;48:495-9.

5. Hong $\mathrm{CH}$, Darling TN, Lee $\mathrm{CH}$. Prevalence of tuberous sclerosis complex in Taiwan: a national population-based study.

Neuroepidemiology 2009;33:335-41.

6. Barello S, Graffigna G, Vegni E. Patient engagement as an emerging challenge for healthcare services: mapping the literature. Nurs Res Pract 2012;2012:, Article ID 905934, 7.

7. Whitehead L, Gosling V. Parent's perception of interactions with health professionals in the pathway to gaining a diagnosis of tuberous sclerosis (TSC) and beyond. Res Dev Disabil 2003;24:109-19.

8. Tuberous Sclerosis Alliance. TSAlliance Web site: http://www. tsalliance.org. An Introduction to Tuberous Sclerosis Complex. 2007, 80 0-2 2 5-6 872 .

9. Curatolo P, Bombardieri R, Jozwiak S. Tuberous sclerosis. Lancet 2008;372:657-68.
10. Huyard C. What, if anything, is specific about having a rare disorder? Patients judgments on being ill and being rare. Blackwell Publishing Ltd Health Expectations, 2009;12:361-70.

11. Dellve L, Samuelsson L, Tallborn A, et al. Stress and well-being among parents of children with rare diseases: a prospective intervention study. J Adv Nurs 2006;53:392-402.

12. Kase BF, Nilsson B. A small-group center. A model trial for activities of a center for rare diseases and syndromes at the National Hospital. Tidsskr Nor Laegeforen 1996;116:1340-4.

13. Olausson A. A socioeconomic case study of rare diseases. Pharmacoeconomics 2002;20(Suppl 3):73-5.

14. Bissler JJ, McCormack FX, Young LR, et al. Sirolimus for angiomyolipoma in tuberous sclerosis complex or lymphangioleiomyomatosis. N Engl J Med 2008;358:140-51.

15. Do Prilleltensky I, Nelson G, Peirson L. The role of power and control in children's lives: an ecological analysis of pathways toward wellness, resilience and problems, Issue Journal of Community \& Applied Social Psychology, Special Issue: Power. Control Health 2001;11:143-58.

16. Wallander J, Varni J, Babani L, et al. Family resources as resistant factors for psychological development in chronically ill and handicapped children. J Pediatr Psychol 1989;14:157-73.

17. Thompson R, Gustafson K. Adaptation to chronic childhood illness. Washington, DC, USA: American Psychological Association, 1996.

18. Thorne SE, Harris SR, Mahoney K, et al. The context of health care communication in chronic illness. Patient Educ Couns 2004;54: 299-306.

19. Teddlie C, Yu F. Mixed methods sampling: a typology with examples. J Mixed Methods Res 2007:1:77-100.

20. Adriaensen MEAPM, Schaefer-Prokop CM, Stijnen T, et al. Prevalence of subependymal giant cell tumors in patients with tuberous sclerosis and a review of the literature. Eur J Neurol 2009;16:691-6.

21. de Ribaupierre S, Dorfmüller G, Bulteau C, et al. Subependymal giant-cell astrocytomas in pediatric tuberous sclerosis disease: when should we operate? Neurosurgery 2007:60:83-9.

22. Bosio AC, Graffigna G, Lozza E 2008. Online focus groups: toward a theory of technique. In: Hansson T. ed. Handbook of digital information technologies: innovations and ethical issues. Idea Group Publishing, 192-212.

23. Graffigna G. Interpersonal exchanges about HIV/AIDS trough different media: a cross-cultural comparison. VDM Verlag, Publishing House Ltd, 2009.

24. Graffigna G, Libreri C, Bosio AC. Online exchanges among cancer patients and caregivers: constructing and sharing health knowledge about time. Qual Res Organ Manag 2012;14:323-37.

25. Lilcon Y, Guba E. Naturalistic inquiry. Sage Publications, 1985.

26. Kübler-Ross E. On death and dying. Routledge, 1969.

27. Prochaska JO, Di Clemente CC. The transtheoretical approach: crossing the traditional boundaries of therapy.. Melbourne, FL: Krieger Publishing Company, 1984.

28. Cohen MS. Families coping with childhood chronic illness: a research review. Fam Syst Health 1999;17:149-64.

29. Kazak AE. Families of chronically ill children: a systems and social-ecological model of adaptation and challenge. J Cons Clin Psy 1989:57:25-30.

30. Houtzager BA, Oort FJ, Hoekstra-Weebers JEHM, et al. Last coping and family functioning predict longitudinal psychological adaptation of siblings of childhood cancer patients. J Ped Psyc 2004:29: 591-605.

31. Hill R. Families under stress. Green-Wood Press, 1949.

32. Hill R, Hansen D. The family in disaster. In: Baker G, Chapman D. eds. Man and society in disaster. New York: Basic Books, 1962:185-220.

33. Baraka L, Kazak A, Meadows A, et al. Families surviving childhood cancer: a comparison of posttraumatic stress symptoms with families of healthy children. J Ped Psyc 1997;22:843-59.

34. Everhart S, Fiese H, Smyth M. A cumulative risk model predicting caregiver quality of life in pediatric asthma. J Ped Psyc 2008;33:809-18.

35. Davison GC. Stepped care: doing more with less. J Cons Clinic Psyc 2000;68:580-5.

36. Gruman J, Holmes-Rovner M, Jeffress D, et al. The engagement behavior framework: a new definition of patient engagement. Washington, DC: Center for Advancing Health, 2009. Retrieved 13 May 2010.

37. Hibbard J, Cunningham P. How engaged are consumers in their health and health care, and why does it matter? Washington, DC Center for Studying Health System Change, 2008. 
38. Bellardita, Graffigna G, Donegani S, et al. Patient's choice of observational strategy for early-stage prostate cancer. Neuropsychol Trends 2012;12:107-16

39. Berwick DM, Nolan TW, Whittington J. The triple aim: care, health and cost. Health Aff 2008;27:759-69.

40. Dellve L, Reichenberg K, Hallberg LRM. Parents coping with caring for their asthmatic child. A grounded theory study. Scand J Disabil Res2000;2:100-13.

41. Graves KN, Shelton TL. Family empowerment as a mediator between family-centered systems of care and changes in child functioning: identifying an important mechanism of change. $J$ Child Fam Stud 2007;16:556-66.

42. Narayanan V. Tuberous sclerosis complex: genetics to pathogenesis. Pediatr Neurol 2003;29:404-9.

43. Prilleltensky I, Nelson G, Peirson L. The role of power and control in children's lives: an ecological analysis of pathways toward wellness, resilience and problems, Issue. J Commun Appl Soc Psychol 2001;11:143-58. Special Issue: Power, Control and Health 